\title{
Mechanical properties of methacrylate-based model dentin adhesives: Effect of loading rate and moisture exposure
}

\author{
Viraj Singh ${ }^{1,2}$, Anil Misra ${ }^{2,3}$, Ranganathan Parthasarathy ${ }^{2,4}$, Qiang Ye $^{2}$, Jonggu Park ${ }^{5}$, and \\ Paulette Spencer ${ }^{1,2}$ \\ ${ }^{1}$ Mechanical Engineering Department, University of Kansas, Lawrence, Kansas 66045-7609 \\ 2Bioengineering Research Center, University of Kansas, Lawrence, Kansas 66045-7609 \\ ${ }^{3}$ Civil, Environmental and Architectural Engineering Department, University of Kansas, Lawrence, \\ Kansas 66045-7609 \\ ${ }^{4}$ Bioengineering Graduate Program, University of Kansas, Lawrence, Kansas 66045-7609 \\ ${ }^{5}$ Materials Research and Development, Johnson \& Johnson Vision Care, Jacksonville, Florida
}

\begin{abstract}
The aim of this study is to investigate the mechanical behavior of model methacrylate-based dentin adhesives under conditions that simulate the wet oral environment. A series of monotonic and creep experiments were performed on rectangular beam samples of dentin adhesive in threepoint bending configuration under different moisture conditions. The monotonic test results show a significant effect of loading rate on the failure strength and the linear limit (yield point) of the stress-strain response. In addition, these tests show that the failure strength is low, and the failure occurs at a smaller deformation when the test is performed under continuously changing moisture conditions. The creep test results show that under constant moisture conditions, the model dentin adhesives can have a viscoelastic response under certain low loading levels. However, when the moisture conditions vary under the same low loading levels, the dentin adhesives have an anomalous creep response accompanied by large secondary creep and high strain accumulation.
\end{abstract}

\section{Keywords}

dentin adhesive; creep; rate-dependence; moisture

\section{INTRODUCTION}

The bond formed at the dentin-adhesive (a-d) interface is arguably the key to successful composite dental restorations and remains its weakest link. ${ }^{1,2}$ In restorative dentistry using polymer composites, the tooth surface is generally pretreated with acids to increase the porosity. Acid-etching extracts the mineral from the dentin to expose the collagen matrix. ${ }^{3}$ The composition of the acid-etched dentin is $30 \%$ collagen and $70 \%$ water. ${ }^{4}$ The adhesive is

(C) 2013 Wiley Periodicals, Inc.

Correspondence to: A. Misra; amisra@ku.edu. 
expected to infiltrate the wet, collagen matrix and photopolymerize to form a solid seal. Acid-etching provides effective mechanical bonding between enamel and adhesive, but bonding to dentin has been fraught with problems. Clinicians frequently find very little enamel available for bonding at the gingival margin of class II composite restorations, and thus, the bond at this margin depends on the integrity of the adhesive seal formed with dentin. 5,6

In the mouth, dentin adhesives are exposed simultaneously to mechanical loads and an environment that experiences fluctuating temperatures and acidic to basic conditions. The synergistic action of the caustic oral environment and mechanical loading accelerates degradation or failure of dentin adhesives, which further causes premature failure of the composite restoration. Regardless of the reason for failure, the role of the dentin adhesive is paramount as the bridging material that provides the mechanism of load transfer between the dentin and the composite. ${ }^{7-9}$ The causes of dentin adhesive failure under the combined influence of chemical and mechanical stress can be broadly categorized into the following: (a) proliferation of surface and subsurface flaws due to the combined effects of mechanical loads and exposure to chemical challenges and (b) change in the chemical nature of the polymer in the form of phase separation, crystallization, or plasticization.

Most dentin adhesive characterization studies are focused on bond strength investigations that by nature incorporate the effects of dentin and composite. ${ }^{10-13}$ Dentin adhesives are viscoelastic materials having rate-dependent mechanical properties; hence, the bond test result should depend on the loading rate. Because bond strength tests are typically preformed at a high loading rate, the dentin adhesive should have a stiffer response that would lead to characteristically higher bond strengths that may not be always representative of the loading conditions under function. Moreover, the bond strength test does not identify the modes of failure. Failure in bond strength testing usually means complete separation of two surfaces, but failure for dentin adhesives can also be described by the magnitude of permanent deformation accumulated. For example, under constant load, dentin adhesives can accumulate large permanent strain without fracturing or breaking. This phenomenon where the specimen does not fracture into two pieces, but has large permanent deformation under a constant load, is defined as creep failure. This phenomenon is clinically relevant, because in the composite restoration, the dentin adhesive might not completely fracture but can deform considerably and create spaces that will be infiltrated by enzymes, bacteria, and oral fluids. The penetration of these agents into the spaces between the tooth and composite will undermine the restoration and lead to recurrent caries, hypersensitivity, and pulpal inflammation.

Therefore, independent characterization of the rate-dependent dentin adhesive mechanical behavior in the presence of water is required to better understand their role in the clinical environment. Currently, these dentin adhesive properties have not been widely investigated. In our previous work, ${ }^{14}$ we have shown that water acts as a plasticizer and decreases the elastic modulus and fatigue life of model dentin adhesives. In this study, we have further explored the effect of water on the mechanical behavior of methacrylate-based dentin adhesives. We note that this study focuses on the adhesive behavior and not on the interaction of the adhesive and the dentin substrate. In particular, we have investigated the 
properties of two model dentin adhesives under creep and rate-dependent monotonic loading in different moisture conditions. The hypothesis of the investigation reported herein is that the mechanical properties of methacrylate-based dentin adhesive are affected by loading rate and moisture content. We have found that these dentin adhesives exhibit various responses under different moisture conditions and loading rates, including an anomalous creep response.

\section{MATERIALS AND METHODS}

\section{Material}

In this study, we have used two formulations of dentin adhesives: (a) control dentin adhesive consisting of 2-hydroxyethylmethacrylate (HEMA, Acros Organics, NJ) and 2,2-bis[4-(2hydroxy-3-methacryloxypropoxy) phenyl]-propane (BisGMA, Polysciences, Warrington, PA) with a mass ratio of 45:55 (HEMA:BisGMA) and (b) experimental formulation consisting of HEMA, BisGMA, and 2-((1,3-bis(methacryloyloxy)propan-2yloxy)carbonyl)benzoic acid (synthesized by our group) ${ }^{15}$ with a mass ratio of 45:30:25. The following photoinitiators (all from Aldrich, Milwaukee, WI) were used in the study: camphorquinone, ethyl-4-(dimethylamino) benzoate, and diphenyliodonium hexafluorophosphate. The amounts of photosensitizer, co-initiator amine, and iodonium salt were fixed at 0.5 mass $\%$ with respect to the total amount of monomer. Continuous shaking and sonication for $48 \mathrm{~h}$ were required to yield well-mixed resin solutions. All the materials in this study were used as received.

\section{Sample preparation}

Rectangular beam samples of cross-sections $1 \mathrm{~mm} \times 1 \mathrm{~mm}$ and length $15 \mathrm{~mm}$ were made by curing the resin in a glass-tubing mold (Fiber Optic Center Inc, \#CV1012, Vitrocom Rectangular Capillary Tubing of Borosilicate Glass). The model adhesives were injected into glass tubes using a micro-pipette, and subsequently, polymerized for $10 \mathrm{~s}$ in a light curing box that has both top and bottom LED plates of irradiance $250 \mathrm{~mW} / \mathrm{cm}^{2}$ and area $6.25 \mathrm{~mm}^{2}$ (LED Curebox, Proto-tech, Portland, OR, USA). The polymerized samples were stored in the dark at room temperature for $2 \mathrm{~d}$ to provide adequate time for postcure polymerization. The samples were then extracted from the glass tubing mold and stored for $3 \mathrm{~d}$ in a vacuum oven in the presence of a drying agent at $37^{\circ} \mathrm{C}$ to remove water that may have been absorbed during sample preparation.

\section{Degree of conversion}

The degree of conversion (DC) of polymerized and stored samples as described above was determined using Raman spectroscopy. Spectra were collected using a LabRAM ARAMIS Raman spectrometer (LabRAM HORIBA Jobin Yvon, Edison, New Jersey) with a HeNe laser $(\lambda=633 \mathrm{~nm}$, a laser power of $17 \mathrm{~mW})$ as an excitation source. To determine the DC, spectra of the uncured resins and beam samples were acquired over a spectral range of 700$1800 / \mathrm{cm}$. The change of the band height ratios of the aliphatic carbon-carbon double bond $(C=C)$ peak at $1640 / \mathrm{cm}$ and the aromatic $\mathrm{C}=\mathrm{C}$ at $1610 / \mathrm{cm}$ (phenyl) in both the cured and uncured states was monitored. ${ }^{16} \mathrm{DC}$ was calculated using the following formula based on the decrease in the intensity band ratios before and after light curing: 


$$
\begin{gathered}
D C(\%)=100\left[1-\left(\mathrm{R}_{\text {cured }} / \mathrm{R}_{\text {uncured }}\right)\right] \\
\mathrm{R}=(\text { band height at } 1640 / \mathrm{cm} / \text { band height at } 1610 / \mathrm{cm}) .
\end{gathered}
$$

\section{Mechanical tests}

Instrument and data interpretation. Bose Electroforce 3200 (Bose Corporation, Electroforce System Group, Eden Praire, Minnesota, USA) was used in a 10-mm 3-point bending configuration for all the mechanical testing. All the tests were performed at room temperature of $25^{\circ} \mathrm{C}$. For comparison of results, the applied load and measured displacement were converted to apparent stresses and strains using the equations of elastic beam theory for long slender beam undergoing small deformations.

Moisture conditions-The monotonic and creep tests were performed under following moisture conditions:

1. Dry (D) series: Beam samples were stored dry and tested dry.

2. Wet (W) series: Beam samples were submerged in water for $5 \mathrm{~d}$ for complete saturation ${ }^{17}$ and then tested submerged in water.

3. Dry to wet $(D+W)$ series: Samples were stored dry and then tested submerged in water.

In addition, a D200 + W series creep tests were performed in which the samples were stored dry and tested in the dry condition for the first 200 minutes and then water was added and the test continued with the samples submerged in water.

Monotonic tests-Static or monotonic tests were performed on dentin adhesives in different moisture conditions to obtain the stress-strain curves $(n=3)$. These tests were performed at two different loading rates of 60 and $2 \mu \mathrm{m} / \mathrm{s}$ to investigate the effect of loading rate on the stress-strain behavior. D + W series tests were performed only at the rate of 2 $\mu \mathrm{m} / \mathrm{s}$.

Creep tests-The creep tests for the two dentin adhesive formulations were performed under stress amplitude of 4.5 MPa $(n=3)$. This low stress amplitude was chosen such that the tested samples are primarily in the linear viscoelastic condition. D200 + W series test was only performed for the control formulation.

Viscoelastic model for dentin adhesive. To understand the viscoelastic behavior of the dentin adhesives in rheological terms, we have used a Prony series ${ }^{14}$ formed by five KelvinVoigt elements connected in series with different retardation times to fit the creep data from dry (series D) and wet (series W) experiments. The creep compliance function in this case is given by the following equation: 
$J(t)=J_{0}+J_{1}\left(1-e^{-\frac{t}{\tau_{1}}}\right)+J_{2}\left(1-e^{-\frac{t}{\tau_{2}}}\right)+J_{3}\left(1-e^{-\frac{t}{\tau_{3}}}\right)+J_{4}\left(1-e^{-\frac{t}{\tau_{4}}}\right)+J_{5}\left(1-e^{-\frac{t}{\tau_{5}}}\right)$

where $\mathrm{J}_{0}, \mathrm{~J}_{1}, \mathrm{~J}_{2}, \mathrm{~J}_{3}, \mathrm{~J}_{4}$, and $\mathrm{J}_{5}$ are creep constants, and $\tau_{1}, \tau_{2}, \tau_{3}, \tau_{4}$, and $\tau_{5}$ are the retardation times associated with each rheological spring-dashpot system. In this study, the retardation time $\tau_{1}, \tau_{2}, \tau_{3}, \tau_{4}$ and $\tau_{5}$ to obtain the best fit were found to be $0.1,100,1000$, 10,000 , and $100,000 \mathrm{~s}$, respectively.

\section{RESULTS}

\section{Degree of conversion}

Three randomly selected samples from each batch (control adhesive and experimental adhesive) were tested for DC measurement. The average value of DC was obtained from spectra acquired from three different locations on the sample. The measured mean DC was found to be $90.0 \%( \pm 1.5 \%)$ and $88.0 \%( \pm 1.25 \%)$ for control and experimental formulations, respectively. Typically for these types of samples, the initial DC that is measured immediately after the polymerization is $8 \%-10 \%$ lower than the final DC after $5 \mathrm{~d}$.

\section{Monotonic tests}

Results of the monotonic testing at different loading rates and three moisture environments are shown in Figure 1. We can observe that under dry conditions (series D), both the control and experimental dentin adhesives have similar apparent stress-strain behavior and show similar influence of loading rates. The effect of loading on the apparent elastic modulus, which is the slope of linear portion of the stress-strain curves, flexural strength, and yield point (defined here as linear limit) are shown in Table I. Flexural strength at a loading rate of $60 \mu \mathrm{m} / \mathrm{s}$ for both experimental and control adhesives in the dry state is approximately 100 $\mathrm{MPa}$, while at $2 \mu \mathrm{m} / \mathrm{s}$ flexural strengths are reduced to approximately $65 \mathrm{MPa}$ as shown in Table I. The apparent elastic modulus is observed to have a small loading rate effect; however, we note that the yield point is achieved at a higher stress and strain under faster loading. When these dentin adhesives are stored and tested in water (series W), the behavior is significantly softer when compared with that in a dry environment. For the control adhesive, the apparent elastic modulus and flexural strength are reduced to 1.2 GPa and 34.5 $\mathrm{MPa}$, respectively, for the loading rate of $60 \mu \mathrm{m} / \mathrm{s}$. Moreover for the experimental formulation, apparent modulus and strength are reduced to $0.96 \mathrm{GPa}$ and $29.5 \mathrm{MPa}$, respectively. Loading rate affects the behavior in wet conditions in a similar way as that in the dry conditions. In contrast, for the case of dry-to-wet moisture condition (series D + W), we observe that (1) the initial part of the apparent stress-strain curve is stiffer, (2) the flexural strengths and yield point are lower, and (3) the apparent stress-strain curve reach asymptote or peak stress at a smaller strain when compared with the curves obtained for samples in completely wet conditions (series W).

\section{Creep}

Results of the creep tests under different moisture conditions are shown in Figure 2. The following observations can be made for results from the different test series: 
1. Series D: For the stored dry and tested dry samples, both of the adhesive formulations showed similar creep behavior. The average instantaneous strain at time, $\mathrm{t}=0$, was approximately $0.23 \%$, and these samples reached asymptotic value of creep strains $0.35 \%$ (in approximately $17 \mathrm{~h}$ ) indicating a linear viscoelastic response.

2. Series W: For the stored wet and tested wet samples, the experimental formulation showed larger creep deformation. The average instantaneous strain for the control adhesive was $0.39 \%$ and that for the experimental adhesive was $0.52 \%$ compared with $0.23 \%$ in the dry condition. After $24 \mathrm{~h}$ of testing, the samples for the control and experimental adhesive formulations had reached asymptotic strain of $0.66 \%$ and $0.88 \%$ strain, respectively, again indicating a viscoelastic linear response.

3. Series $\mathrm{D}+\mathrm{W}$ : For the stored dry and tested wet samples, the instantaneous strain for both of the adhesives is $0.24 \%$, which is consistent with the dry condition results from series D test. However, as the test progressed, the samples from both the control and experimental adhesive formulations experienced considerable deformations that exceeded what the samples had in series W tests. During the 48-h testing period, the control and experimental adhesive samples accumulated approximately $2.6 \%$ and $4.0 \%$ strain, respectively, and did not reach an asymptotic value.

4. Series $\mathrm{D} 200+\mathrm{W}$ : These series of tests are conducted on the control adhesive formulation only. As expected the instantaneous strain in this series was $0.23 \%$ consistent with the dry condition. Moreover, the behavior was similar to the series $\mathrm{D}$ result for the first $200 \mathrm{~min}$ when the dry conditions were maintained. However, once the water was introduced into the bath, samples experienced increasing creep deformation. During the 48-h testing period, these samples accumulated approximately $3.5 \%$ strain and did not reach an asymptotic value.

The creep response shown by the series D and W samples in Figure 2 was fitted using Prony series given in equation (1). The predicted curves along with experimental curves are shown in Figure 3. A total of six unknown creep coefficients were required to be evaluated to fit the data. These creep coefficients were obtained using the nonlinear least-square subroutine from Matlab 2007b. The calculated Prony series parameters are shown in Table II along with $\mathrm{R}^{2}$ goodness of fit for both wet and dry conditions. The least-square fitting was performed under the constraint that the creep constants were nonnegative. ${ }^{14}$

\section{DISCUSSION}

In this study, we have evaluated the mechanical behavior of two different dentin adhesive formulations in different moisture conditions. To this end, we have performed (1) monotonic tests at two different loading rates, and (2) creep tests at low loading levels where the behavior could be considered to linear viscoelastic. We have observed significant effect of loading rate on the failure strength and the linear limit (yield point) of the stress-strain curve, which is expected for rate-dependent material such as polymers. We have also found that the dentin adhesive formulations become softer, and both the apparent elastic modulus and flexural strength decrease when the samples are stored in water (series W). It is important to 
note that when the dentin adhesives are tested dry to wet (series D $+\mathrm{W}$ ) at the slow loading rate, the failure strength is the lowest and the failure occurs at a smaller deformation ( $2 \%$ vs. $3 \%-4 \%)$. This is important from the clinical perspective where the composite restoration comes in contact with mechanical loading and the wet, oral environment simultaneously. If we compare the two adhesive formulations, when tested dry to wet (series D + W), the experimental adhesive has the lower failure strength of $16.75 \mathrm{MPa}$ as compared to $21.5 \mathrm{MPa}$ for the control adhesive. This is expected because of the more hydrophilic nature of the experimental formulation. ${ }^{15}$ The behavior observed in this study suggests that these features are critical for the evaluation of dentin adhesives. The rate-dependent and the moisture sensitive behavior is ignored in many bond strength tests that are routinely used for evaluating dentin adhesives.

We have also observed significant differences in the creep response of the two dentin adhesives in the different moisture conditions. Creep curves for a material can be divided into three major regions: primary creep, secondary creep, and tertiary creep as depicted in Figure 4. Primary creep is the initial region where the creep rate is high. Secondary creep is the region following primary creep where the creep rate becomes smaller and constant. Tertiary creep is marked by the region after secondary creep where creep rate becomes high again, which leads to specimen failure. Creep curves obtained from the experiments on dentin adhesives can be categorized into these creep regions.

For the series D samples of both control and experimental adhesives, creep deformation started at $0.23 \%$ strain at time, $t=0$, and reached an asymptotic value of $0.32 \%$ strain after $17 \mathrm{~h}$ of testing. These samples show only primary creep beyond which they reach an asymptote. Series W samples compared with series D accumulated larger strain in $1440 \mathrm{~min}$ (24 h) of testing indicating softer behavior. The instantaneous strain in series W was roughly twice the instantaneous strain in series $\mathrm{D}$, indicating plasticization of dentin adhesive due to storage in water. Similar to series D, series W samples only show primary creep.

The creep response of dry to wet tested samples (series D + W) shown in Figure 2 is very different from that of series $\mathrm{D}$ and $\mathrm{W}$ samples. Instantaneous deformation for this series is similar to series D indicating that the material is initially dry, but the behavior deviates from series D as the water diffuses into the sample. These samples undergo considerable secondary creep deformation with increasing creep rate suggestive of an imminent tertiary creep. Remarkably, the secondary creep rate decreases after some time, and subsequently, the specimen deform under a new stable creep rate. In the results shown in Figure 2, the creep rate appears to slow down to a new stable rate after $1440 \mathrm{~min}(24 \mathrm{~h})$. It is also notable that after $2880 \mathrm{~min}(48 \mathrm{~h})$, the samples had accumulated $2.6 \%$ and $4 \%$ strain for the control and experimental adhesives, respectively. These strain levels far exceed the values obtained in series $\mathrm{W}$ tests under completely wet conditions. In this article, we refer to this type of response as anomalous creep response of dentin adhesives. Series D200 + W samples show a similar anomalous creep behavior as that of series D + W samples. In this case, for the first $200 \mathrm{~min}$, the response follows the dry samples consistent with results from series D test. Once the water is introduced into the bath, the behavior deviates as the creep rate increases, and the samples accumulate strains similar to series D + W samples. 
The anomalous creep behavior seen in the series D + W and D200 + W samples are linked to the simultaneous effects of mechanical loading and water diffusion into the polymer network. When the model dentin adhesives samples are submerged, the water begins to diffuse and plasticize the polymer network by disrupting or further weakening the so-called weak interactions (noncovalent bonds), such as Van de Waals, electrostatic, and hydrogen bonds, in the polymer network. The plasticization process continues till the sample is completely saturated. During this period, the material can be expected to be in nonequilibrium state and susceptible to additional deformation under external loading. Therefore, we expect that the polymer behavior, such as anomalous creep or the loss of strength, will be affected by both the testing time, $T_{t}$, and the time for saturation, $T_{s}$. For further discussion, we define the ratio of saturation and testing time as $R=T_{s}: T_{t}$, which is similar to Deborah number defined as the ratio of relaxation time to interaction time. ${ }^{18}$ When the saturation time is very large compared with testing time, that is, $R \gg 1$, the sample remains dry during the test. On the other hand, when the saturation time is small compared with testing time, that is, $R \ll<1$, the sample behaves as completely saturated. In either of these cases, the sample is in an equilibrium state with respect to moisture intake during the mechanical loading. When the saturation and the testing time are of similar order, that is $R \approx 1$, the sample is in nonequilibrium state with respect to water intake and experiences anomalous creep or loss of strength. Saturation time depends on the rate of water intake or diffusion properties of the polymer as well as the sample geometry. Furthermore, the diffusion properties are influenced by the polymer structure, stiffness of the crosslinked polymer network, and its hydrophilicity. ${ }^{17}$ The time required for complete saturation of the samples tested in this article is $24-48 \mathrm{~h}$ based on mass change with time measurements reported by our group. ${ }^{17}$ The series $\mathrm{D}+\mathrm{W}$ creep tests have a total testing time $\sim 48 \mathrm{~h}$. The testing time required for series $D+W$ under monotonic tests till peak stress is $\sim 3 \mathrm{~h}$. Based on our diffusion studies, ${ }^{17}$ the highly stressed outer ligaments should also experience substantial water invasion at $\sim 3 \mathrm{~h}$. Consequently, the effects of the nonequilibrium material state are seen in both creep and monotonic series D + W tests.

For series D tests, the sampled remain dry, so no anomalous creep is observed. For the series W samples, once the sample is saturated and the diffusion process complete, the sample achieves an equilibrium state. Because no external energy is applied in the form of mechanical loads during water diffusion or, the accompanying plasticization, anomalous deformations are not observed. Because the activation energy of saturated sample is lower compared with dry sample because of plasticization, larger deformations compared with dry samples are produced. Thus, based on the experimental results, it can be concluded that when the moisture content of dentin adhesive is at extreme level and constant, either completely saturated or completely dry during mechanical testing, no anomalous creep or loss of strength is observed. When the moisture content of the dentin adhesive is changing during mechanical loading, anomalous creep and loss of strength are observed. Similar moisture-induced effects have been described for other materials like wood, wool, and Kevlar polyurethane. These effects have been attributed to molecular mobility, physical ageing, and sorption induced stress gradients. ${ }^{19-21}$ 
We also note that the behavior of the series $D$ and $W$ samples is linear viscoelastic and can be modeled by the use of Prony series described in our previous work. ${ }^{14}$ However, the creep behavior shown by series D $+\mathrm{W}$ and D200 + W samples cannot be predicted using linear viscoelastic Prony series. More representative physics-based mathematical models are needed, which take into account the moisture-induced damage of noncovalent bonds in these types of polymers (see for example Ref. 22).

Finally, we note that the composition of the adhesive formulations used in this study do not necessarily duplicate the current commercial dentin adhesives. Current dentin adhesives used in the clinic may be composed of different co-monomer systems. These clinical systems are likely to have similar behavior because of the hydrophilic component although the quantitative results may be different. Moreover the DC may have an effect on the quantitative results but the overall behavior is expected to be similar.

\section{SUMMARY AND CONCLUSIONS}

In this study, two types of model methacrylate-based dentin adhesives were studied for their mechanical properties under conditions that simulate the wet oral environment. Ratedependent monotonic tests and creep tests were performed on rectangular beam samples of these dentin adhesives in three-point bending configuration under different moisture conditions. The monotonic test results showed that model dentin adhesives have significant rate-dependent behavior. We found that the failure strength and yield point decreased with a decrease in loading rate. In addition, these tests showed that the failure strength is low, and the failure occurs at a smaller deformation when the tests are performed under continuously changing moisture conditions. The creep test results showed that under constant moisture conditions, either completely dry or wet, the model adhesives exhibit only primary creep at low loading levels. In these conditions, the creep response can be characterized as linear viscoelastic. In contrast, the rate of creep and total creep strain increased substantially under the same low load level when the moisture content of dentin adhesive was continuously changing while a constant load was applied. Creep behavior of dentin adhesives are important in many clinical situation, such as for patients with bruxing habits. In these cases, there is small relaxation time between high load conditions, and the restoration will experience repeated stress cycles without complete relaxation leading to accumulation of the creep strains. Similarly in clinical situation where anomalous creep behavior is relevant, the dentin adhesive might not completely fracture but deform significantly. The resultant large creep strains will cause permanent deformation in restoration, which can create spaces that can be infiltrated by enzymes, bacteria, and oral fluids that lead to recurrent caries, hypersensitivity, pulpal inflammation, and the failure of the restoration. In addition, the conventional linear viscoelastic models such as Maxwell or Kelvin Voigt are not sufficient to explain the rate-dependent and anomalous creep behavior under varying moisture conditions. More rigorous physics-based mathematical models that take into account the water-induced damage on polymer network are needed for characterizing and developing effective dentin adhesives. 


\section{Acknowledgments}

Contract grant sponsor: National Institutes of Health/National Institute of Dental and Craniofacial Research; contract grant numbers: R01DE014392, 3R01DE014392-08S1, and R01 DE022054

\section{REFERENCES}

1. Spencer P, Ye Q, Park J, Topp EM, Misra A, Marangos O, Wang Y, Bohaty BS, Singh V, Sene F, Eslick J, Camarda K, Katz JL. Adhesive/dentin interface: The weak link in the composite restoration. Ann Biomed Eng. 2010; 38:1989-2003. [PubMed: 20195761]

2. Spencer P, Ye Q, Misra A, Bohaty BS, Singh V, Parthasarathy R, Sene F, Goncalves SEDP, Laurence J. Durable bonds at the adhesive/dentin interface: an impossible mission or simply a moving target? Braz Dent Sci. 2012; 15:4-18.

3. Marangos O, Misra A, Spencer P, Katz JL. Scanning acoustic microscopy investigation of frequency-dependent reflectance of acid- etched human dentin using homotopic measurements. IEEE Trans Ultrason Ferroelectr Freq Control. 2011; 58:585-595. [PubMed: 21429849]

4. Pashley DH, Ciucchi B, Sano H, Horner JA. Permeability of dentin to adhesive agents. Quintessence Int. 1993; 24:618-631. [PubMed: 8272500]

5. Kleverlaan CJ, Feilzer AJ. Polymerization shrinkage and contraction stress of dental resin composites. Dent Mater. 2005; 21:1150-1157. [PubMed: 16040118]

6. Roulet JF. Benefits and disadvantages of tooth-coloured alternatives to amalgam. J Dent. 1997; 25:459-473. [PubMed: 9604577]

7. Misra A, Spencer P, Marangos O, Wang Y, Katz JL. Micromechanical analysis of denti00dhesive interface by the finite element method. J Biomed Mater Res B Appl Biomater. 2004; 70B:56-65. [PubMed: 15199584]

8. Misra A, Spencer P, Marangos O, Wang Y, Katz JL. Parametric study of the effect of phase anisotropy on the micromechanical behavior of dentin-adhesive interface. J R Soc Interface. 2005; 2:145-157. [PubMed: 16849175]

9. Singh V, Misra A, Marangos O, Park J, Ye Q, Kieweg SL, Spencer P. Fatigue life prediction of dentin-adhesive interface using micromechanical stress analysis. Dent Mater. 2011; 27:e187-e195. [PubMed: 21700326]

10. Armstrong S, Geraldeli S, Maia R, Raposo LH, Soares CJ, Yamagawa J. Adhesion to tooth structure: a critical review of "micro" bond strength test methods. Dent Mater. 2010; 26:e50-e62. [PubMed: 20045179]

11. Armstrong SR, Boyer DB, Keller JC. Microtensile bond strength testing and failure analysis of two dentin adhesives. Dent Mater. 1998; 14:44-50. [PubMed: 9972150]

12. Roeder L, Pereira PN, Yamamoto T, Ilie N, Armstrong S, Ferra-cane J. Spotlight on bond strength testing-Unraveling the complexities. Dent Mater. 2011; 27:1197-203. [PubMed: 21944280]

13. Yiu CKY, King NM, Pashley DH, Suh BI, Carvalho RM, Carrilho MRO, Tay FR. Effect of resin hydrophilicity and water storage on resin strength. Biomaterials. 2004; 25:5789-5796. [PubMed: 15147825]

14. Singh V, Misra A, Marangos O, Park J, Ye Q, Kieweg SL, Spencer P. Viscoelastic and fatigue properties of model methacrylate-based dentin adhesives. J Biomed Mater Res B Appl Biomater. 2010; 95:283-290. [PubMed: 20848661]

15. Park J, Ye Q, Singh V, Kieweg SL, Misra A, Spencer P. Synthesis and evaluation of novel dental monomer with branched aromatic carboxylic acid group. J Biomed Mater Res B Appl Biomater. 2012; 100:569-576.

16. Park JG, Ye Q, Topp EM, Misra A, Spencer P. Water sorption and dynamic mechanical properties of dentin adhesives with a urethane-based multifunctional methacrylate monomer. Dent Mater. 2009; 25:1569-1575. [PubMed: 19709724]

17. Parthasarathy R, Misra A, Park J, Ye Q, Spencer P. Diffusion coefficients of water and leachables in methacrylate-based crosslinked polymers using absorption experiments. J Mater Sci Mater Med. 2012; 23:1157-1172. [PubMed: 22430592] 
18. Israelachvili, JN. Intermolecular and Surface Forces. Academic Press; Burlington, MA: 2011. p. 674

19. Habeger CC, Coffin DW. The role of stress concentrations in accelerated creep and sorptioninduced physical aging. J Pulp Pap Sci. 2000; 26:145-157.

20. Habeger CC, Coffin DW, Hojjatie B. Influence of humidity cycling parameters on the moistureaccelerated creep of polymeric fibers. J Polymer Sci B Polymer Phys. 2001; 39:2048-2062.

21. Wang JZ, Dillard DA, Kamke FA. Transient moisture effects in materials. J Mater Sci. 1991; 26:5113-5126.

22. Misra A, Singh V. Micromechanical model for viscoelastic materials undergoing damage. Continuum Mech Therm. 2013; 25:343-358. 


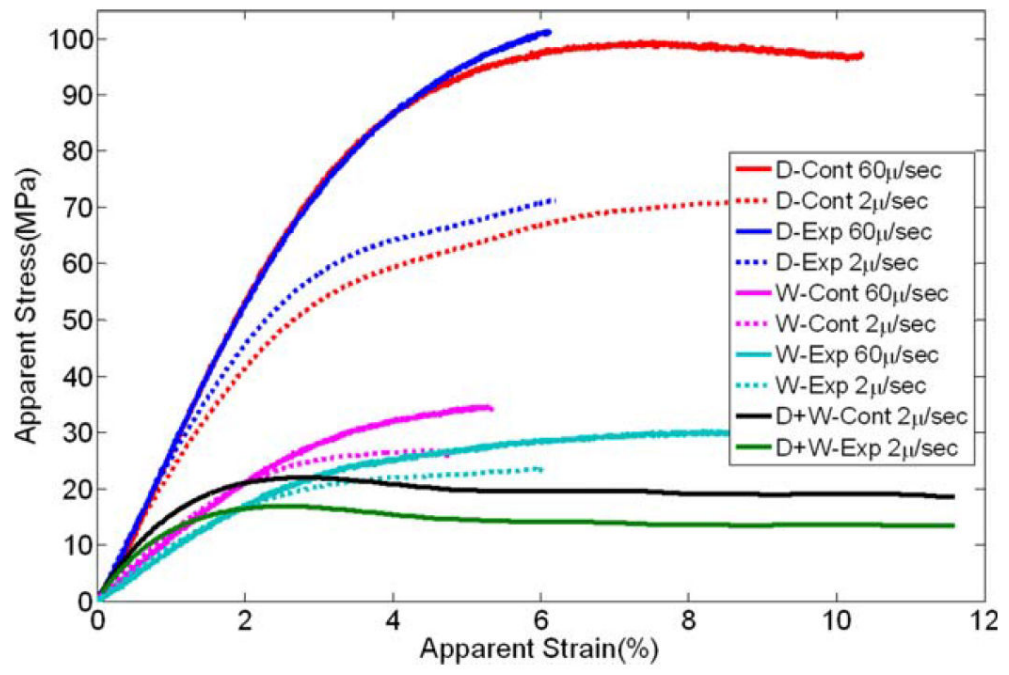

FIGURE 1.

Apparent stress-strain curves for control and experimental dentin adhesives in different moisture conditions and different loading rates. 


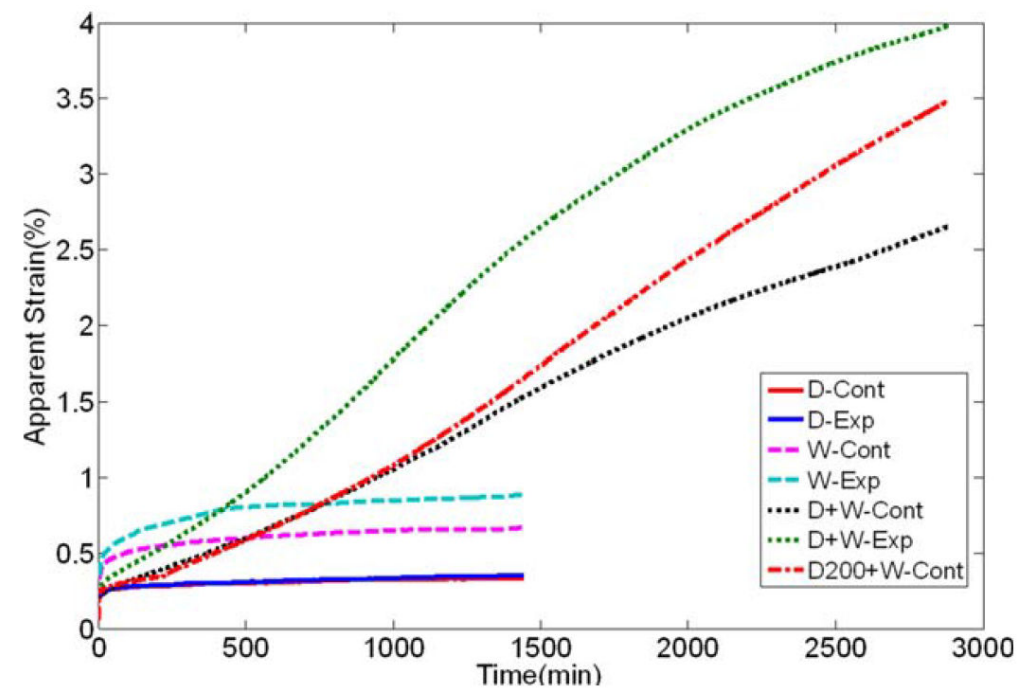

FIGURE 2.

Creep curves for control and experimental dentin adhesives in different moisture conditions at apparent stress amplitude of 4.5 MPa. 


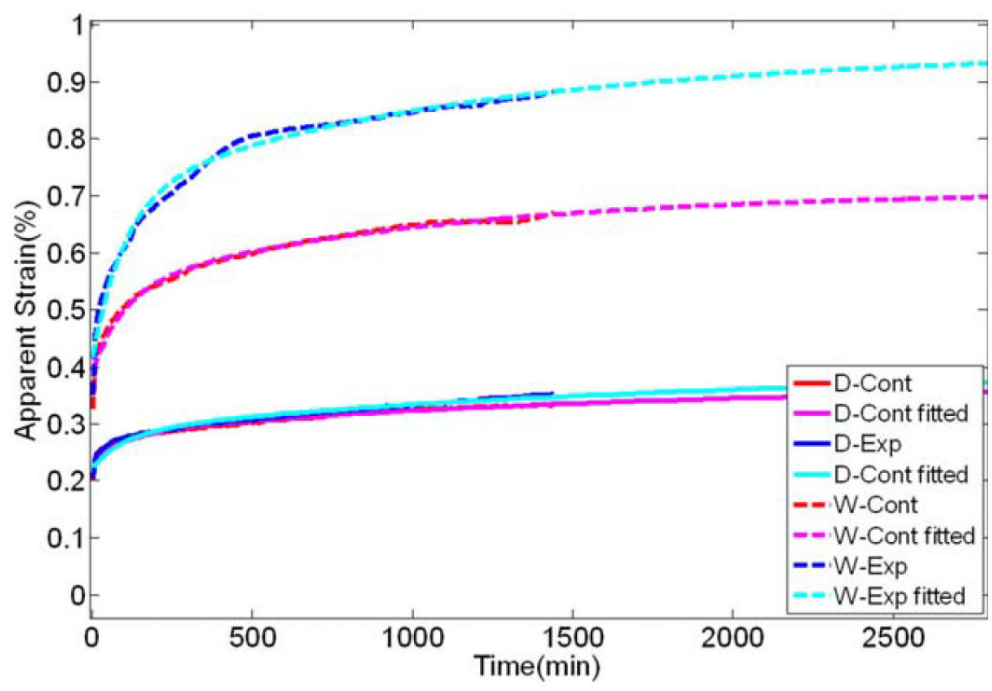

FIGURE 3.

Predicted curves using Prony series for control and experimental formulation in dry and wet conditions. 


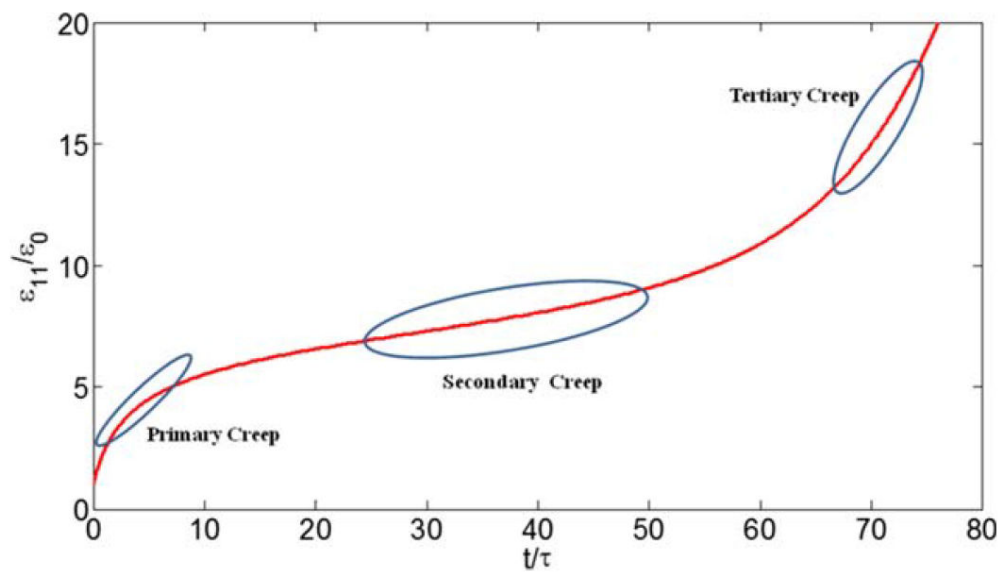

FIGURE 4.

Schematic of creep response showing primary, secondary, and tertiary regions. 


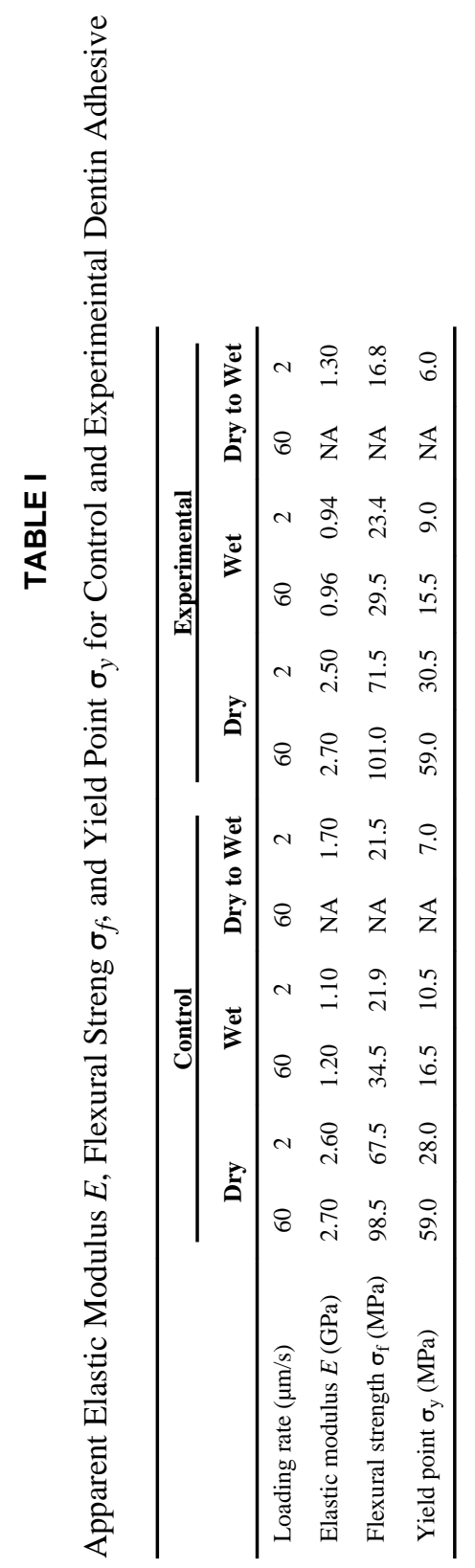


TABLE II

Prony Series Parameters for Creep Compliance Function

\begin{tabular}{|c|c|c|c|c|}
\hline \multirow[b]{3}{*}{ Unit $\left(\mathbf{m}^{2} / \mathbf{N}\right)$} & \multicolumn{2}{|c|}{ Control } & \multicolumn{2}{|c|}{ Experimental } \\
\hline & Dry $\times 10^{-10}$ & Wet $\times 10^{-10}$ & Dry $\times 10^{-10}$ & Wet $\times 10^{-10}$ \\
\hline & $R^{2}=0.9668$ & $R^{2}=0.9822$ & $R^{2}=0.9812$ & $R^{2}=0.9836$ \\
\hline $\mathrm{J}_{0}$ & 2.44 & 4.30 & 2.30 & 4.60 \\
\hline $\mathrm{J}_{1}$ & 2.80 & 4.41 & 2.93 & 4.60 \\
\hline $\mathrm{J}_{2}$ & 0.94 & 3.15 & 1.13 & 6.20 \\
\hline $\mathrm{J}_{3}$ & 1.02 & 3.87 & 0.00 & 5.50 \\
\hline $\mathrm{J}_{4}$ & 3.78 & 0.00 & 0.00 & 0.00 \\
\hline $\mathrm{J}_{5}$ & 0.0 & 0.00 & 104.30 & 0.00 \\
\hline
\end{tabular}

